\title{
Peculiarities of cell death mechanisms in neutrophils
}

\author{
B Geering ${ }^{1}$ and H-U Simon ${ }^{*, 1}$
}

Analyses of neutrophil death mechanisms have revealed many similarities with other cell types; however, a few important molecular features make these cells unique executors of cell death mechanisms. For instance, in order to fight invading pathogens, neutrophils possess a potent machinery to produce reactive oxygen species (ROS), the phagocyte nicotinamide adenine dinucleotide phosphate (NADPH) oxidase. Evidence is emerging that these ROS are crucial in the execution of most neutrophil cell death mechanisms. Likewise, neutrophils exhibit many diverse granules that are packed with cytotoxic mediators. Of those, cathepsins were recently shown to activate pro-apoptotic B-cell lymphoma-2 (Bcl-2) family members and caspases, thus acting on apoptosis regulators. Moreover, neutrophils have few mitochondria, which hardly participate in ATP synthesis, as neutrophils gain energy from glycolysis. In spite of relatively low levels of cytochrome $c$ in these cells, the mitochondrial death pathway is functional. In addition to these pecularities defining neutrophil death pathways, neutrophils are terminally differentiated cells, hence they do not divide but undergo apoptosis shortly after maturation. The initial trigger of this spontaneous apoptosis remains to be determined, but may result from low transcription and translation activities in mature neutrophils. Due to the unique biological characteristics of neutrophils, pharmacological intervention of inflammation has revealed unexpected and sometimes disappointing results when neutrophils were among the prime target cells during therapy. In this study, we review the current and emerging models of neutrophil cell death mechanisms with a focus on neutrophil peculiarities.

Cell Death and Differentiation (2011) 18, 1457-1469; doi:10.1038/cdd.2011.75; published online 3 June 2011

\section{Significance of Neutrophil Death}

Neutrophil death during homeostasis. Each day, more than $10^{11}$ circulating neutrophils undergo cell death in humans. ${ }^{1}$ It is generally agreed that the physiological form of cell death in neutrophils is apoptosis. Aged neutrophils have for a long time been considered to die within a short period of time by spontaneous (also called constitutive) apoptosis under healthy conditions, in order to maintain homeostatic cell numbers, ${ }^{2}$ a process that can be mimicked in vitro by culturing the cells in the absence of sufficient amounts of survival cytokines. ${ }^{3}$ However, recent data suggest a neutrophil lifespan of 5 days under in vivo conditions. ${ }^{4}$ Although the mechanisms of neutrophil destruction in vivo are poorly defined, senescent neutrophils are thought to be removed by Kupffer cells in the liver, by red pulp macrophages in the spleen and by stromal macrophages in the bone marrow. In studies examining the distribution of radiolabeled senescent neutrophils in mice, the relative distribution of radiolabeled cells was equally split between bone marrow, liver, and spleen. ${ }^{5}$

Neutrophil death during inflammation. The control of granulocyte cell death and subsequent clearance of the apoptotic cell is not only crucial for maintaining homeostasis, but also paramount to an efficient resolution of inflammation. Neutrophils undergo spontaneous apoptosis at inflamed sites. ${ }^{6}$ In addition, these cells are killed at the site of inflammation by death receptor-induced apoptosis. For instance, infiltrating macrophages release death receptor ligands, such as tumor necrosis factor- $\alpha$ (TNF- $\alpha$ ) and Fasligand, ${ }^{7}$ both triggering neutrophil apoptosis. Moreover, the phagocytosis of certain bacteria by neutrophils also accelerates neutrophil apoptosis at sites of infection. ${ }^{8}$ Neutrophil apoptosis not only contributes to the regulation of neutrophil cell numbers, but also guaranties the safe

\footnotetext{
${ }^{1}$ Institute of Pharmacology, University of Bern, Bern, Switzerland

${ }^{*}$ Corresponding author: H-U Simon, Institute of Pharmacology, University of Bern, Friedbuehlstrasse 49, CH-3010 Bern, Switzerland. Tel: + 41-31-632-3281;

Fax: + 41-31-632-4992; E-mail: hus@pki.unibe.ch

Keywords: apoptosis; autophagy; death signaling; inflammation; reactive oxygen species; neutrophilic granulocytes

Abbreviations: AIF, apoptosis-inducing factor; Apaf-1, apoptotic protease-activating factor-1; ATG, autophagy gene; Bad, Bcl-2-associated death promoter; Bak, Bcl-2 homologous antagonist/killer; Bax, Bcl-2-associated X protein; Bcl-2, B-cell lymphoma-2; BH3, Bcl-2 homology-3; Bid, BH3-interacting domain death agonist; Bik, Bcl-2 interacting killer; Bim, Bcl-2 interacting protein; CAMP, cyclic AMP; CDK, cyclin-dependent kinase; CGD, chronic granulomatous disease; Diablo, direct IAP-binding protein with low pl; ERK, extracellular signal-regulated kinase; G-CSF, granulocyte colony-stimulating factor; GPCR, G protein-coupled receptor; HtrA2, hightemperature requirement A2; IFN, interferon; JAK, janus kinase; LPS, lipopolysaccharide; Lyn, Ick/yes-related novel; MAPK, mitogen-activated protein kinase; Mcl-1, myeloid cell leukaemia-1; NADPH, nicotinamide adenine dinucleotide phosphate; NET, neutrophil extracellular trap; PCNA, proliferating cell nuclear antigen; Phox, phagocyte oxidase; PI3K, phosphoinositide 3-kinase; PKB, protein kinase B; PS, phosphatidylserine; Puma, p53 upregulated modulator of apoptosis; Rac2, Ras-related C3 botulinum toxin substrate 2; ROS, reactive oxygen species; Smac, second mitochondria-derived activator of caspases; STAT, signal transducer and activator of transcription; TLR, toll-like receptor; TNF, tumor necrosis factor; TRAIL, TNF-related apoptosis-inducing ligand; XIAP, X-linked inducer of apoptosis protein

Received 10.2.11; revised 27.4.11; accepted 29.4.11; Edited by G Melino; published online 03.6.11
} 
disposal of engulfed bacteria, ${ }^{8}$ leads to a loss of functional properties in neutrophils and drives the production of antiinflammatory cytokines through clearance of the apoptotic cell by resident or infiltrating macrophages. The interplay of these processes thus promotes the resolution of inflammation.

The importance of a tight regulation of neutrophil death is evident under pathological conditions during hereditary or inflammatory diseases. For instance, neutropenia as a consequence of accelerated neutrophil death during differentiation and/or upon full maturation can occur following chemotherapy, ${ }^{9}$ bone marrow transplantation ${ }^{10}$ or can be found in patients suffering from severe congenital, cyclic and idiopathic neutropenia, ${ }^{11}$ or subjects lacking the expression of $\mathrm{BCl}-\mathrm{xL}$ in neutrophil precursors. ${ }^{12}$ In all these cases, the resulting neutropenia is associated with bacterial and fungal infections.

On the other hand, delayed neutrophil death results in neutrophilia. Longer survival of neutrophils due to inhibition of apoptosis contributes to the accumulation of these cells at inflammatory sites. ${ }^{3}$ In vivo, cytokines and growth factors are major regulators of neutrophil survival. Neutrophilia can be found in patients suffering from infectious and autoimmune diseases, respectively. Neutrophilia frequently results in excessive release of toxic metabolites causing tissue injury and subsequent organ dysfunctions. In order to tackle abnormal neutrophil cell death in these diseases, it is essential to understand the molecular death mechanisms of these cells under both physiological and pathological conditions.

\section{Death Molecules in Neutrophils}

During apoptosis, neutrophils show the typical morphological characteristics associated with this kind of cell death, ${ }^{13}$ such as rounding-up of the cell, reduction in cellular volume and nuclear fragmentation. Biochemically, neutrophils activate pro-apoptotic Bcl-2 family members and caspases, loose their mitochondrial transmembrane potential, fragment DNA and expose phosphatidylserine (PS) on their surface. As described in detail below, due to certain particularities that come with neutrophil biology, mature neutrophils express reduced levels of anti-apoptotic proteins as compared with their longlived, immature precursors ${ }^{14,15}$ and use ROS derived from the NADPH oxidase as well as granular proteases to induce and control apoptosis. We discuss below the molecular components involved in the regulation of neutrophil apoptosis (see also Table 1).

Caspases. Neutrophils can engage the intrinsic or extrinsic death pathway that both culminate in activation of effector caspases. These cells were reported to express a variety of initiator and effector caspases, including caspases$1,-3,-4,-6,-7,-8,-9,-14 .^{16-19}$ Neutrophils also express the X-linked inhibitor of apoptosis protein (XIAP) that blocks effector caspase activity, ${ }^{17}$ and possibly cellular inhibitor of apoptosis protein-1 (c-IAP-1), c-IAP-2, and, at least under inflammatory conditions, surviving. ${ }^{15,17}$ It should be noted that the expression of XIAP and survivin was predominantly detected in immature neutrophils. ${ }^{15}$
Bcl-2 family. The balance between the expression of the pro-apoptotic and anti-apoptotic members of the Bcl-2 family of proteins is thought to be an important component determining the lifespan of mature neutrophils, and changes in the ratio of pro- and anti-apoptotic Bcl-2 family members have been observed during neutrophil apoptosis. ${ }^{18}$ Neutrophils were shown to express the pro-apoptotic Bcl-2 family members $\mathrm{Bcl}-2$-associated $\mathrm{X}$ protein (Bax), Bcl-2 homologous antagonist/killer (Bak), Bcl-2-associated death promoter (Bad), Bcl-2 homology-3 (BH3)-interacting domain death agonist (Bid), Bcl-2 interacting protein (Bim) and $\mathrm{Bcl}-2$ interacting killer (Bik) at the protein level under nonstimulated conditions. ${ }^{18,20-22}$ Although genetic deletion of Bax did not impact on neutrophil viability, bax/bak double knockout mice showed increased neutrophil numbers, ${ }^{23}$ suggesting functional importance of Bak in the regulation of neutrophil life span. Also bim knockout mice have increased neutrophil numbers, and granulocytes derived from $\mathrm{bim}^{-/-}$ mice demonstrated increased viability as compared with control cells. ${ }^{14,22,24}$ Recent data from in vitro differentiated murine neutrophils and neutrophils derived from knockout mice support a major role of Bim, but imply that, in addition to Bim, Noxa is a main driver of neutrophil apoptosis because genetic depletion of both proteins resulted in increased neutrophil viability as compared with neutrophils derived from single knockout mice. ${ }^{25}$

Expression of the anti-apoptotic Bcl-2 members Bcl-2 and $\mathrm{Bcl}-\mathrm{w}$ was not detected at the protein level or is very low in mature neutrophils, ${ }^{18,20,21}$ while $\mathrm{Bcl}-2$ protein is readily detectable in immature neutrophils. ${ }^{14}$ Not surprisingly, neutrophils of $b c l-2$ or $b c l-w$ knockout mice demonstrated normal death kinetics in vitro as compared with wild-type mice. ${ }^{22}$ Whether $\mathrm{BCl}-\mathrm{xL}$ protein is expressed in neutrophils is highly controversial. ${ }^{18,20,21,26,27}$ Although the anti-apoptotic A1 has only been detected at the mRNA level in neutrophils, ${ }^{18}$ a1-a $a^{-/-}$ neutrophils have accelerated apoptosis, ${ }^{28}$ suggesting some functional importance in the regulation of neutrophil lifespan. Myeloid cell leukaemia-1 (Mcl-1) was proposed to be the predominant anti-apoptotic Bcl-2 homolog in neutrophils, as its expression was consistently detected at mRNA and protein level ${ }^{18,20,21}$ and its protein levels closely correlate with neutrophil survival kinetics. $^{29}$ In addition, mice with a conditional deletion of $\mathrm{mcl}-1$ in neutrophils showed severe defects in neutrophil survival due to an increase in apoptosis. ${ }^{30}$ More recently, it was shown that murine neutrophil numbers are reduced because of apoptosis during differentiation, if $m c l-1$ is knocked out in the myeloid lineage. ${ }^{31}$

Mitochondria. One of the hallmarks of neutrophil physiology is a reduced number of mitochondria. Thus, mitochondrial respiration in mature neutrophils is low and mitochondria hardly participate in the synthesis of ATP. ${ }^{19}$ Therefore, mitochondrial poisons do not influence cellular functions in neutrophils. ${ }^{32}$ Nevertheless, neutrophil mitochondria form a highly developed network, ${ }^{33}$ release mitochondrial DNA upon activation, ${ }^{34}$ possess a transmembrane potential and contain pro-apoptotic proteins (cytochrome $c$, second mitochondria-derived activator of caspases (Smac)/direct IAP-binding protein with low pl (Diablo), high-temperature requirement A2 (HtrA2)/Omi, 
Table 1 Death-associated proteins expressed in human and murine neutrophils

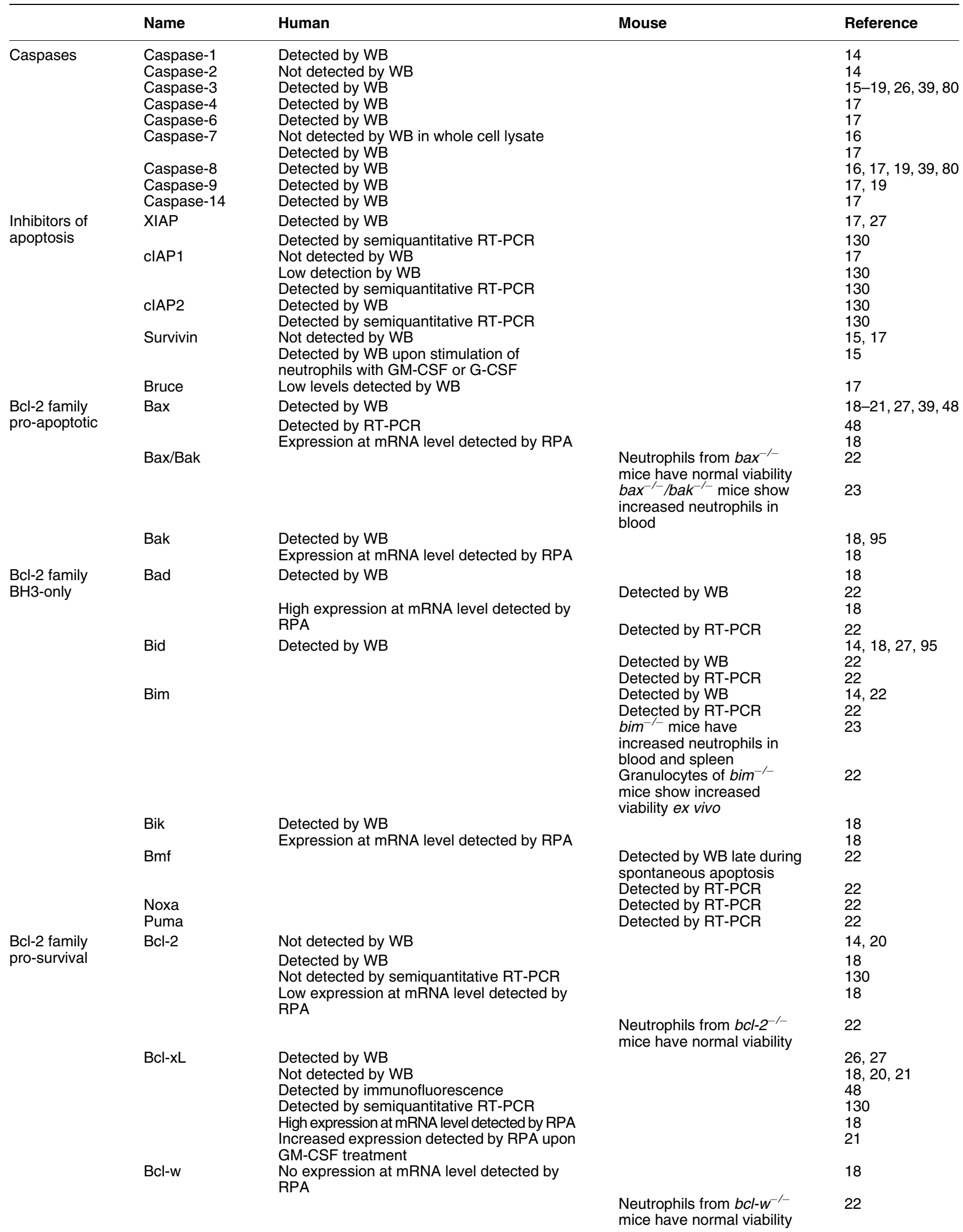




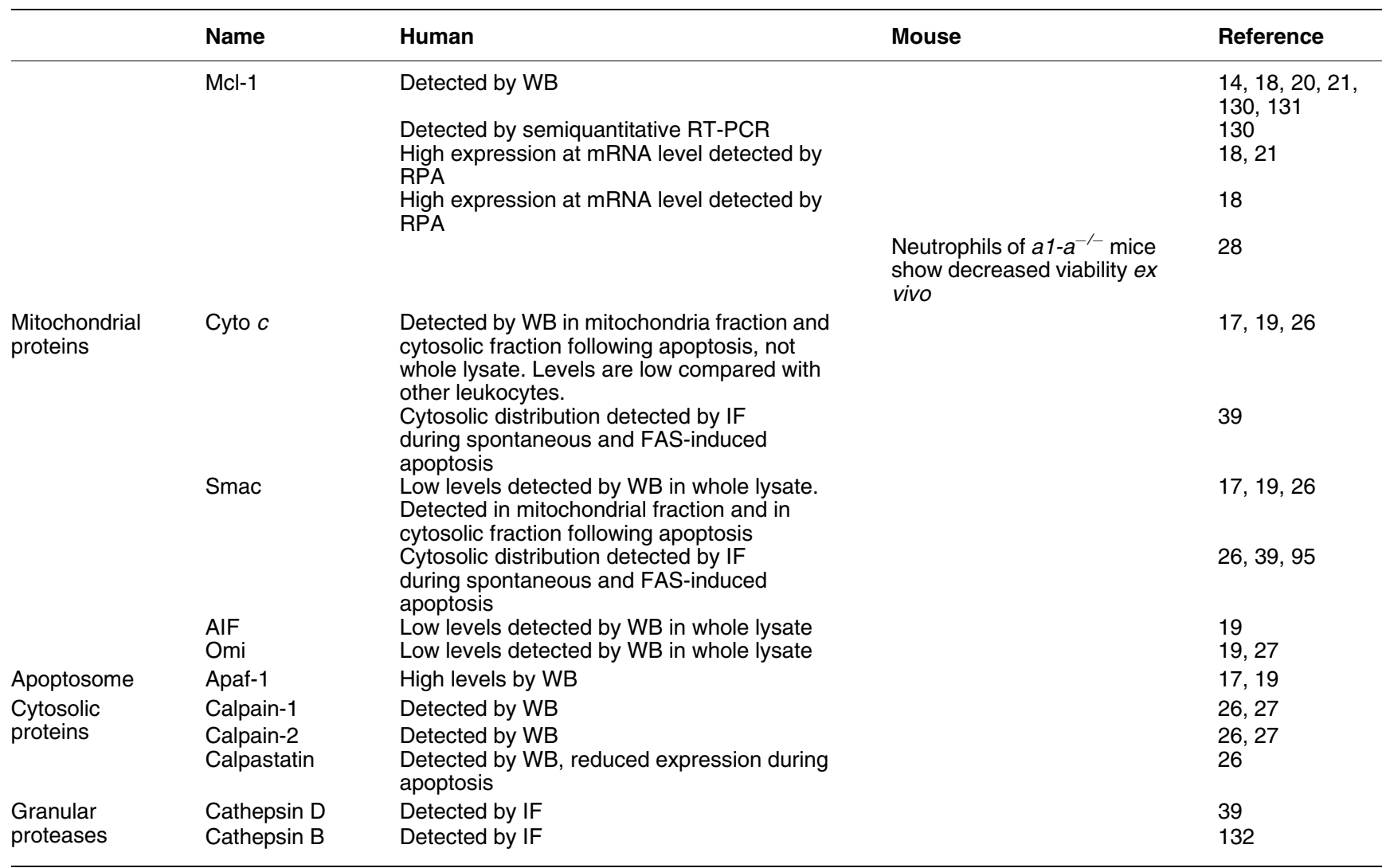

apoptosis-inducing factor (AIF)), which are released into the cytosol upon induction of apoptosis. ${ }^{17,19,26}$ Although neutrophils contain low levels of cytochrome $c,{ }^{19}$ they were shown to require cytochrome $c$ to activate caspases. ${ }^{17}$ The reduced levels of cytochrome $c$ seem to be compensated by increased expression of cytosolic apoptotic protease-activating factor 1 (Apaf-1) in neutrophils. ${ }^{19}$ Besides cytochrome $c$, Smac appears to be important for optimal caspase-3 activation in neutrophils. ${ }^{26}$ These results therefore indicate that neutrophil mitochondria, although deficient in respiration, still preserve the potential to support apoptotic caspase activation.

Reactive oxygen species (ROS). A second hallmark of neutrophil physiology that drives cell death is the relatively high concentration of ROS that are generated by the NADPH oxidase $^{35}$ in order to fight microbial intruders. In resting cells, NADPH oxidase is inactive, and its components are distributed between the cytosol and membranes. When cells are activated, the cytosolic components of the phagocyte oxidase (phox), such as $\mathrm{p} 47^{\text {phox }}, \mathrm{p} 67^{\text {phox }}, \mathrm{p} 40^{\text {phox }}$, and Rasrelated C3 botulinum toxin substrate 2 (Rac2), migrate to granule $(>80 \%)$ and cell membranes (approximately $5 \%$ ), ${ }^{36}$ where they associate with the membrane-bound components to assemble the catalytically active enzyme causing the socalled respiratory burst. As ROS have not only been detected extracellularly (by lucigenin, luminal, isoluminol) but also intracellularly (by DHR-123, luminal, DCFH-DA), ${ }^{37}$ evidence is accumulating that they participate as signaling molecules in cellular pathways. Thus, the majority of molecular pathways causing neutrophil apoptosis were shown to be dependent on ROS generation. ${ }^{38}$ However, excessive ROS production upon cellular stimulation or the impairment of anti-oxidant defense mechanisms may also result in other neutrophil cell death forms (see also Figure 1), as ROS can damage essential molecules, such as lipids, proteins and DNA. In order to prevent necrosis caused by ROS, cells have developed several ROS scavengers, including catalase, glutathione peroxidase, glutathione reductase and thioredoxin reductase.

Proteases. A third hallmark of neutrophil physiology are their granules, which contain cytotoxic compounds that are used to kill invading pathogens. Proteases within these granules constitute parts of the apoptotic cascade. Thus, cathepsins were shown to be released from azurophilic granules during apoptosis and to process caspase- 8 and Bid, respectively, leading to caspase- 3 activation. ${ }^{39,40}$

Moreover, the cytosolic non-caspase cysteine protease calpain mediates neutrophil apoptosis. Calpains are constitutively active in neutrophils, ${ }^{41}$ but are kept in check by the endogenous inhibitor calpastatin. During neutrophil apoptosis, calpastatin is degraded ${ }^{26,42}$ and calpains were shown to cleave $\mathrm{Bax}^{26}$ and autophagy gene 5 (Atg5), ${ }^{43}$ and to deactivate XIAP, ${ }^{27}$ thus causing neutrophil apoptosis. 


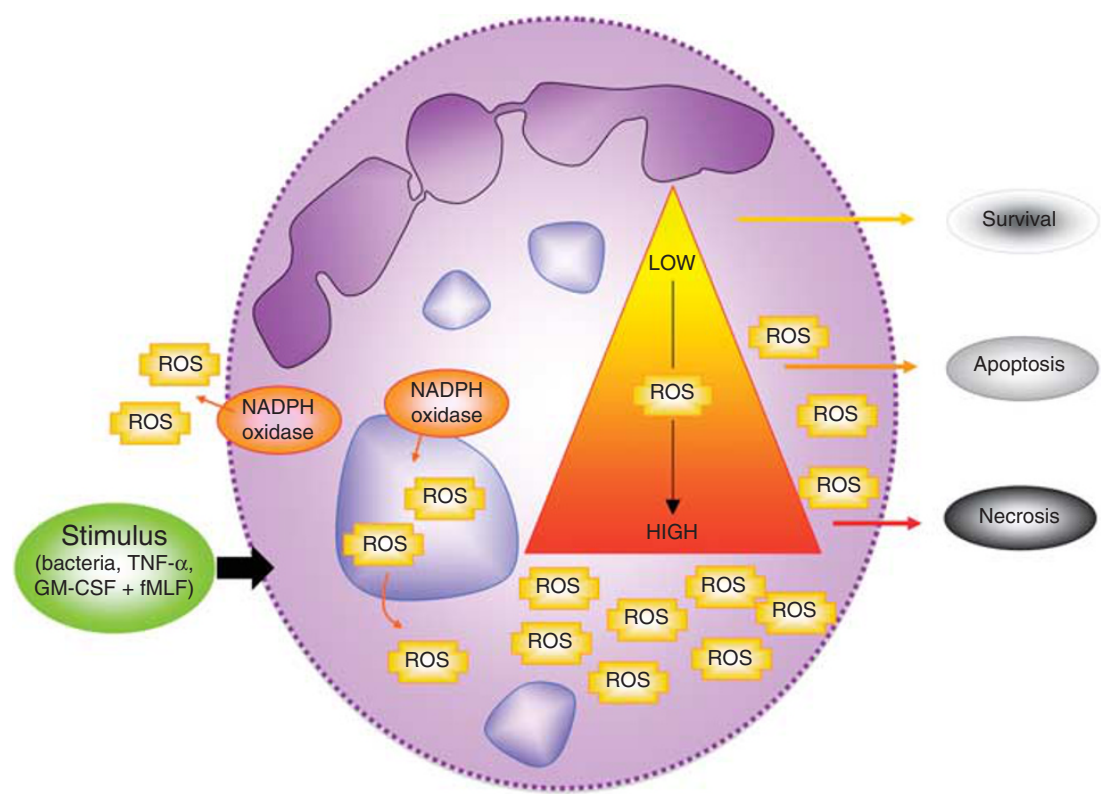

Figure 1 ROS-mediated neutrophil cell death. Upon exposure of neutrophils to various stimuli (e.g. bacteria, TNF- $\alpha$ or GM-CSF + fMLF), the NADPH oxidase is assembled at cellular and granular membranes and becomes activated. This activation results in extracellular and intracellular ROS generation. Depending on the level and - likely also - localization of ROS produced by the NADPH oxidase, neutrophils may die by apoptosis or necrosis, but may also show increased survival

Inhibitors of cyclin-dependent kinases. Two recent additions to the list of molecules that may regulate neutrophil apoptosis are the cyclin-dependent kinases $(\mathrm{CDK})^{44,45}$ and proliferating cell nuclear antigen (PCNA). ${ }^{46}$ As neutrophils do not undergo cell division and are stopped in G0 phase, both groups of molecules have long been considered irrelevant for neutrophil biology. Neutrophils were shown to constitutively express CDK1, CDK2 and CDK5 at the protein level. ${ }^{44}$ Expression of these molecules in mature neutrophils is likely at a much lower level than in precursor cells, as CDK2, CDK4 and CDK6 protein expression is largely diminished in mature neutrophils as compared with promyelocytes. ${ }^{47}$ Nevertheless, treatment of neutrophils with R-roscovitine, an inhibitor of CDK2, CDK7 and CDK9, results in neutrophil apoptosis ex vivo and in the resolution of inflammation in established animal models. ${ }^{44}$ As R-roscovitine was subsequently shown to downregulate protein expression of $\mathrm{Mcl}-1,{ }^{45}$ this drug likely modulates neutrophil lifespan by controlling the expression of Bcl-2 family members.

The endogenous cyclin-dependent kinase inhibitor p21 may constitute a link between the effects of R-roscovitine on neutrophil apoptosis with the one of PCNA. PCNA is highly expressed in the cytosol of mature neutrophils (while it can be mainly found in the nucleus of most other cell types) and is constitutively bound to pro-caspases, presumably to prevent their activation. ${ }^{46} \mathrm{~A}$ decrease in PCNA protein expression resulted in increased neutrophil apoptosis, while stimulation of neutrophils with G-CSF triggered an increase in PCNA protein expression. Interestingly, a short peptide sequence of p21 could interfere with binding of PCNA to its interaction partners (e.g. pro-caspases), and p21 interference was shown to result in increased neutrophil apoptosis. ${ }^{46}$ Thus, inhibitors of cyclin- dependent kinases may target neutrophil lifespan through repression of cyclin-dependent kinases and PCNA.

\section{Survival Molecules in Neutrophils}

Prolonged neutrophil survival is desired under conditions of bacterial or fungal infection. However, delayed neutrophil apoptosis has also been associated with several acute and chronic inflammatory diseases frequently resulting in unwanted tissue damage. The retardation of apoptosis in mature neutrophils appears to be largely mediated by exposure of the cells to pro-survival stimuli, ${ }^{48}$ especially cytokines including granulocyte colony-stimulating factor (GCSF), ${ }^{49,50}$ granulocyte macrophage (GM)-CSF, ${ }^{49-51}$ and interferon (IFN)- $\gamma^{49,52}$ Furthermore, ATP ${ }^{53}$ and leukotriene $B 4^{54}$ were reported to delay neutrophil apoptosis. Inconsistent reports have been published on the effect of lipopolysaccharide (LPS), ${ }^{4,49,51} \mathrm{C} 5 \mathrm{a}^{50,51}$ and TNF- $\alpha^{55}$ on neutrophil lifespan.

Although a detailed analysis of the molecular mechanisms that have been described upon the different pro-survival stimuli go beyond the scope of this review, we would like to give a short overview of the most important players downstream of pro-survival receptors. Thereby, a distinction can be made between stimuli that trigger activation of tyrosine kinases upon receptor ligation (e.g. G-CSF, GM-CSF) and those that activate $G$ protein-coupled receptors (GPCR; e.g. leukotriene B4).

Tyrosine kinases. Early work suggested activation of tyrosine kinases upon GM-CSF stimulation in neutrophils, ${ }^{56}$ and Ick/yes-related novel (Lyn) was subsequently identified as one of the main players in transducing GM-CSF survival 
signals in neutrophils. ${ }^{57}$ Activation of tyrosine kinases upon receptor ligation results in activation of the janus kinase (Jak)/signal transducers and activators of transcription (STAT), phosphoinositide 3-kinase (PI3K) and mitogenactivated protein kinase (MAPK) pathways in neutrophils.

Jak/Stat pathway. GM-CSF stimulation of neutrophils results in Jak2 phosphorylation and activation of several STAT proteins. ${ }^{21}$ Increased phosphorylation and transcriptional activity of STAT proteins subsequently yields enhanced protein expression of $\mathrm{Mcl}-1$. In keeping with this, inhibition of Jak by small molecule inhibitor AG-490 before GM-CSF stimulation reduces Mcl-1 levels and viability as compared with control neutrophils. ${ }^{21}$

PI3K pathway. GM-CSF stimulation of neutrophils furthermore triggers activation of the PI3K signaling pathway, ${ }^{21,58,59}$ which is generally assessed by the phosphorylation status of the downstream PI3K effector Akt/protein kinase $B$ (PKB). Phosphorylation of Akt upon GM-CSF stimulation was reduced by pre-treatment of neutrophils with inhibitors to PI3Ks, correlating with a partial reduction in $\mathrm{Mcl}-1$ protein expression. ${ }^{21}$ Moreover, GM-CSF stimulation was shown to result in the cytosolic accumulation of $\mathrm{Bad}^{59}$ and the phosphorylation of $\mathrm{Bax},{ }^{60}$ which could be blocked by the PI3K inhibitor LY294002. Thus, the increase in neutrophil survival following GM-CSF stimulation of neutrophils was partially decreased when PI3Ks were inhibited, ${ }^{21,58,59}$ suggesting that the PI3K signaling pathway may regulate GM-CSF-induced survival by controlling expression, phosphorylation and subcellular localization of Bcl-2 family members. In contrast to these results, GM-CSF-induced neutrophil survival was shown to be PI3K-independent, as blocking of neither PI3K activity by LY294002 nor Akt by SH-6 impacted on neutrophil viability. ${ }^{61}$

MAPK pathway. Survival factors, such as GM-CSF, also trigger extracellular signal-regulated kinase (ERK) activation and pharmacological inhibitors against ERK prevent survival induced by these factors. ${ }^{58}$ The ERK pathway was subsequently shown to regulate $\mathrm{Mcl}-1$ protein levels and may thus impact on neutrophil viability. ${ }^{62}$ In contrast to ERK activation, which has mainly been implicated in neutrophil survival, activation of the MAPK p38 seems to occur in neutrophils either exposed to pro-survival or pro-apoptotic stimuli. For example, GM-CSF was shown to increase p38 phosphorylation ${ }^{63}$ resulting in phosphorylation and subsequent inactivation of caspase-3 and caspase-8. ${ }^{64}$ However, p38 phosphorylation was also detected upon TNF- $\alpha$ treatment ${ }^{65,66}$ or cellular stresses, ${ }^{67}$ decreasing neutrophil survival under these conditions by phosphorylation and activation of the NADPH oxidase complex, ${ }^{68}$ resulting in ROS generation. Contrary to these reports, prosurvival (e.g. GM-CSF) and pro-apoptotic (e.g. anti-FAS antibody) stimuli were also demonstrated not to impact on in vitro p38 kinase activity. ${ }^{69}$ Thus, the role of p38 in the control of neutrophil survival is unclear.

CAMP. The molecular mechanism of neutrophil survival downstream of GPCRs has not been addressed in detail.
Yet, PKA and PKB, two kinases that are activated downstream of GPCRs, may trigger the elevation of intracellular cyclic AMP (CAMP), which was shown to be anti-apoptotic by blocking the loss in mitochondrial potential. ${ }^{70}$

Nuclear factor kappa B (NF- $\boldsymbol{B}$ B). Activation of PI3K and MAPK signaling pathways induces transcriptional activity of $\mathrm{NF}-\kappa \mathrm{B}$. NF- $\kappa \mathrm{B}$ was shown to be critically involved in enhancing neutrophil survival; ${ }^{71}$ however, the transcriptional targets of $\mathrm{NF}-\kappa \mathrm{B}$ triggering neutrophil survival have not been evaluated in detail. ${ }^{71}$ In addition to the prosurvival stimuli mentioned above, also hypoxia induces prolonged neutrophil survival under in vitro conditions. ${ }^{72}$ Survival signaling upon hypoxia involved the activation of HIF- $1 \alpha$ and the NF- $\kappa$ B transcription pathway. ${ }^{73}$ Increased survival under conditions of low oxygen concentrations may be important for the function of neutrophils during inflammation.

\section{Neutrophil Apoptosis in the Absence of Survival Signals}

Upon maturation and release into the blood stream, neutrophils quickly run through an apoptosis program unless stimulated for survival. Spontaneous neutrophil apoptosis is crucial for maintaining homeostatic neutrophil numbers. The initial trigger of this spontaneous apoptosis in neutrophils is not known (Figure 2). However, it is generally hypothesized that spontaneous apoptosis is an intrinsic process, that is the signal to initiate apoptosis originates within the cell. In keeping with this, neutrophil spontaneous apoptosis was shown to be independent of the interaction between death receptors and their ligands. ${ }^{74,75}$ Thus, neutrophils from CD95-deficient mice undergo constitutive apoptosis at the same rate as neutrophils from control mice. ${ }^{76}$

Different starting points of spontaneous neutrophil apoptosis could be envisaged: (1) an increase in ROS and/or (2) changes in the expression levels of pro- versus anti-apoptotic proteins due to low levels of transcription and translation coupled with a short half-life of anti-apoptotic proteins. Most studies using small molecule inhibitors against the Jak/STAT, PI3K or MAPK pathway did not demonstrate a significant increase in viability of spontaneously dying neutrophils as compared with control cells, ${ }^{58,59,69}$ suggesting that spontaneous apoptosis is induced independent of these signaling pathways.

ROS-induced neutrophil apoptosis. The hypothesis that ROS may be inducers of spontaneous apoptosis is based on several independent observations. Anti-oxidants such as the glutathione precursor $\mathrm{N}$-acetylcysteine ${ }^{77}$ and catalase ${ }^{69}$ delay neutrophil apoptosis and similarly, hypoxia increases neutrophil survival. ${ }^{72}$ In line with these findings, the intracellular glutathione concentration is reduced during apoptosis, shifting the redox balance in neutrophils over time. ${ }^{78} \mathrm{~A}$ role for the NADPH oxidase as the main generator of ROS during spontaneous apoptosis stems from observations in neutrophils derived from patients with chronic granulomatous disease (CGD) that lack a functional NADPH oxidase. CGD neutrophils show increased viability as compared with neutrophils from healthy donors. ${ }^{39,77,79,80}$ 


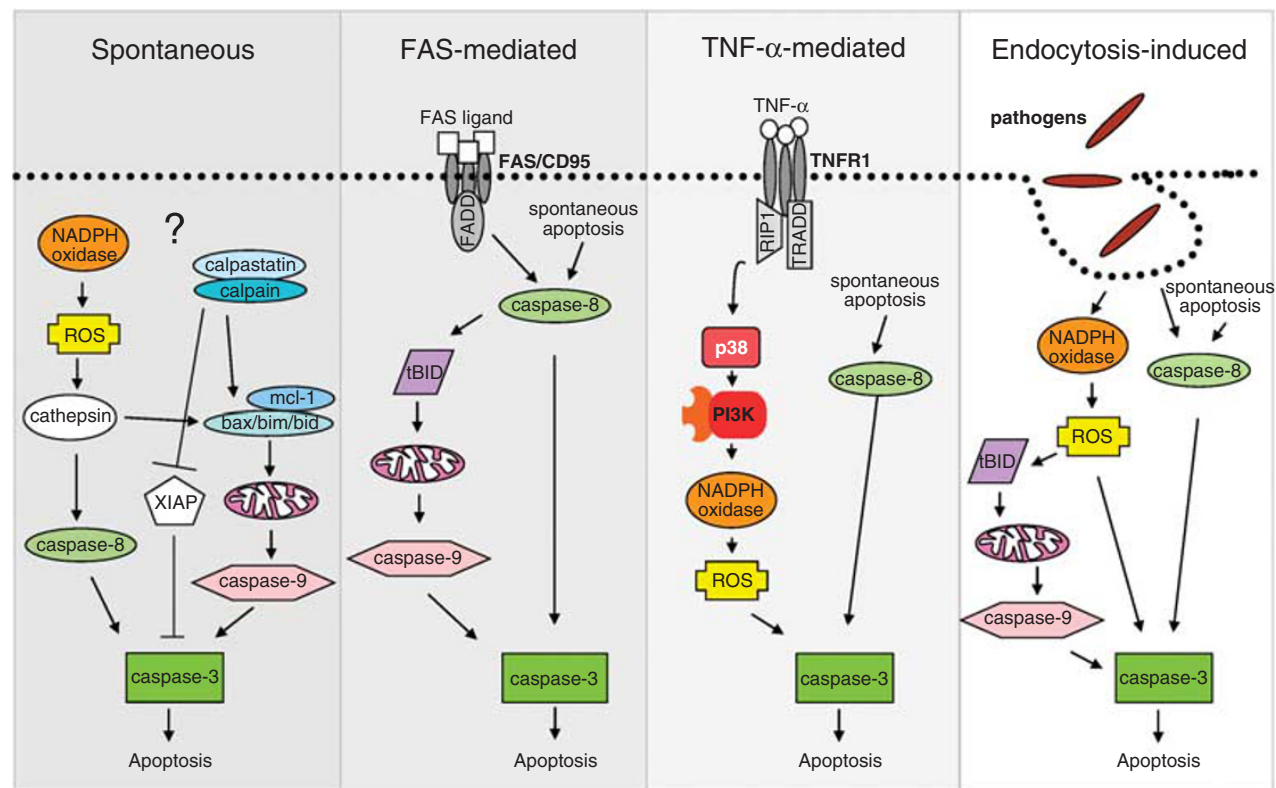

Figure 2 Molecular mechanisms of neutrophil apoptosis. Neutrophils use different molecular pathways for the execution of apoptosis. Although spontaneous and FASinduced apoptosis are heavily dependent on the mitochondrial death pathway, TNF- $\alpha$ - and endocytosis-induced apoptosis were shown to be mediated by ROS generation

Thus, the potential increase in ROS in aging neutrophils may be due to decreased glutathione or constitutive production of ROS by NADPH oxidase. Glutathione may directly inhibit caspase- 8 and caspase- 3 activity $^{81}$ and hence decreased glutathione during the course of spontaneous apoptosis may result in increased caspase activity. Although not many direct targets of ROS have been elucidated, in neutrophils, ROS were shown to activate acid sphingomyelinase that results in increased ceramide levels. ${ }^{78}$ Ceramide contributes to neutrophil apoptosis by increasing caspase-3/ -8, -9 activity. ROS also induce release of cathepsin $D$ from azurophilic granules, leading to caspase-8 activation. ${ }^{39}$ Moreover, ROS inhibits class IB PI3K p110 $\gamma$ resulting in reduced $\mathrm{PIP}_{3}$ levels and Akt phosphorylation. ${ }^{82}$ In summary, an increased redox balance within apoptotic neutrophils likely results in manifold induction of the death machinery.

Neutrophil apoptosis induced by low transcriptional activity. In neutrophils, inhibition of protein synthesis is sufficient to accelerate apoptosis, ${ }^{83}$ suggesting that all elements of the death machinery are continuously available in mature neutrophils. Thus, the high rate of spontaneous apoptosis may be explained, at least in part, by the constitutive and stable expression of a range of proapoptotic proteins and/or by a short half-life of anti-apoptotic proteins coupled with low levels of transcription and translation reported in neutrophils. ${ }^{29,84}$ These findings may indicate that neutrophil apoptosis is initially kept in check by newly synthesized, short-lived anti-apoptotic proteins. One of these anti-apoptotic proteins that was shown to be decreased during neutrophil spontaneous apoptosis is calpastatin. ${ }^{26,42} \mathrm{~A}$ decrease in calpastatin may release the constitutively active calpains to cleave Bax into an active fragment ${ }^{26}$ and deactivate XIAP. ${ }^{27}$ Also the anti-apoptotic
$\mathrm{Bcl}-2$ family member $\mathrm{Mcl}-1$ has a high turnover and its protein expression decreases during apoptosis. ${ }^{20}$ This is in contrast to expression of pro-apoptotic Bcl-2 proteins, such as Bax, which have a relatively long half-life. ${ }^{85}$ During neutrophil aging, reduced $\mathrm{Mcl}-1$ expression may therefore result in free Bax levels that mediate apoptosis. The regulation of translation may thus be decisive in the outcome of neutrophil viability.

The upstream apoptosis signaling (be it ROS-driven or due to low transcriptional activity) will likely converge at the level of caspases. Caspase-8 processing was detected during spontaneous apoptosis ${ }^{26,86}$ and consequently blocking of initiator caspases using IEDT-inhibitor, resulted in delayed spontaneous apoptosis. ${ }^{86}$ Also caspase- 9 processing was observed in neutrophils ${ }^{19}$ and functional inactivation of caspase- 9 resulted in decreased neutrophil apoptosis. ${ }^{86}$ Initiator caspase activity results in the activation of effector caspases and in neutrophils, caspase-3 processing and activation during the course of spontaneous apoptosis was reported by various laboratories. ${ }^{26,81}$

\section{Neutrophil Apoptosis Mediated by Death Receptors}

Activation of neutrophils with members of the TNF cytokine family, such as FASL or TNF- $\alpha$, can result in apoptosis. For instance, apoptosis induction has consistently been reported in neutrophils upon stimulation of FAS/ CD95. ${ }^{26,79,81}$ Neutrophil apoptosis induced by FAS/CD95 activation may be considered an anti-inflammatory mechanism, as it should reduce neutrophil numbers without the release of granule contents. In keeping with this, FASL is overexpressed at immunoprivileged sites to avoid inflammatory responses ${ }^{87}$ and the development of inflammatory diseases, such as rheumatoid arthritis, was recently shown 
to be dependent on the suppression of FASL expression by Foxo3a in neutrophils, at least in an experimental model. ${ }^{88}$ Moreover, neither GM-CSF, G-CSF nor IFN- $\gamma$ could block anti-FAS antibody-induced neutrophil apoptosis, further pointing to the possibility that this pathway is important for the limitation of inflammatory responses. ${ }^{52}$ In contast to these data, inflammatory neutrophils have been reported to be resistant to pro-apoptotic signals resulting from FAS ligation ${ }^{89}$ and G-CSF, GM-CSF, IFN- $\gamma$ or TNF- $\alpha$ priming suppressed FAS-mediated neutrophil apoptosis, ${ }^{90}$ calling for further studies to solve these contradictory results. Besides FASL, evidence for anti-inflammatory actions of TNF- $\alpha$ has also been obtained from several in vivo studies. For instance, genetic ${ }^{91}$ or functional ${ }^{92}$ neutralization of TNF- $\alpha$ enhanced neutrophil inflammatory reactions after infection.

FAS/CD95-induced neutrophil apoptosis. Neutrophils possess a functional FAS receptor, ${ }^{93}$ constitutively express FASL, ${ }^{90}$ and are highly susceptible to FAS-induced apoptosis. $^{90}$ Yet only aggregated or membrane-bound FASL can induce apoptosis, as soluble FASL was reported to trigger neutrophil chemotaxis. ${ }^{94}$

At the molecular level, FAS-induced apoptosis in neutrophils seems to be carried out as described in many other cells (Figure 2). FAS signaling was shown to be caspase dependent, as blocking caspases with pan-caspase inhibitor Z-VAD-FMK rescues cells from FAS-induced cell death in neutrophils. ${ }^{26,79,81}$ Upon receptor ligation, caspase-8 activation is followed by increased caspase- 3 activity. ${ }^{81}$ Evidence is accumulating that neutrophils represent type II cells, which employ the mitochondria-dependent death machinery for execution of FAS-induced apoptosis. For instance, FASmediated neutrophil apoptosis accelerates $\mathrm{Bid}^{95}$ and calpainmediated BAX cleavages, ${ }^{26}$ increases mitochondrial permeability, ${ }^{81}$ enhances mitochondrial release of cytochrome $c$ and Smac $^{26,96}$ compared with neutrophils undergoing spontaneous apoptosis. Moreover, neutrophils derived from bid knockout mice were partially protected from FAS-induced apoptosis, ${ }^{66}$ suggesting that Bid is essential in FAS-mediated neutrophil cell death.

The impact of ROS in FAS-induced neutrophil apoptosis is controversial. Although one report showed that neutrophils from CGD patients have similar apoptosis kinetics after antiFAS Ab stimulation as control cells, ${ }^{79}$ another study suggests that neutrophils from CGD patients undergo FAS-mediated apoptosis with much slower kinetics than healthy neutrophils. ${ }^{77}$ In line with this second study, augmented intracellular glutathione and blocking intracellular ROS by NAC inhibited FAS-induced neutrophil apoptosis, ${ }^{81,89}$ suggesting that ROS may contribute to FAS-mediated neutrophil apoptosis. It should be noted, however, that generation of ROS upon FAS ligation of neutrophils is diminutive as compared with ROS levels produced following TNF- $\alpha$ or phorbol myristate acetate (PMA; a protein kinase $\mathrm{C}$ activator) stimulation. ${ }^{66}$

TNF- $\alpha$-induced neutrophil apoptosis. In contrast to FAS-mediated neutrophil apoptosis, the molecular mechanisms of TNF- $\alpha$-induced cell death seem to differ strikingly in neutrophils as compared with many other cell types (Figure 2). Neutrophils express the two known TNF- $\alpha$ receptors TNFR1 and TNFR2,55 and stimulation of neutrophils with TNF- $\alpha$ has been shown to induce, delay or have no effect on neutrophil apoptosis. ${ }^{84}$ The diverse outcome of TNF- $\alpha$ stimulation seems to depend on TNF- $\alpha$ concentrations, ${ }^{97}$ duration of stimulation ${ }^{98}$ and activation of co-stimulatory molecules, such as integrins. ${ }^{97,99,100}$

TNF- $\alpha$-induced neutrophil apoptosis is mediated by caspase activity, as blocking neutrophils with low concentrations of zVAD-FMK inhibits cell death. ${ }^{16,101}$ However, whether TNF- $\alpha$ stimulation results in caspase-8 activation is controversial. Although TNF- $\alpha$ stimulation was shown to increase caspase-8 processing $^{102}$ and activation ${ }^{103}$ and blocking of caspase- 8 by Z-IETD-FMK delayed TNF- $\alpha$-induced neutrophil apoptosis, ${ }^{100,101}$ other reports suggest that stimulation of TNF receptor does not involve caspase-8 processing or activation. ${ }^{66,104}$ As compared with the uncertain role of caspase-8 upon TNF receptor ligation, caspase-3 processing and activation was reported unequivocally upon TNF- $\alpha$ stimulation. ${ }^{66,102,104}$

In further contrast to FAS stimulation of neutrophils, TNF receptor stimulation does not seem to engage the mitochondrial death pathway. Bid cleavage was not observed $^{66}$ and no changes in the mitochondrial transmembrane potential were detected, ${ }^{105}$ no release of cytochrome $c$ was measured, ${ }^{66}$ and blocking caspase- 9 by Z-LEHD-FMK did not significantly delay neutrophil apoptosis. ${ }^{100,101}$ In keeping with this, neutrophils derived from bid knockout mice undergo TNF- $\alpha$-induced apoptosis to the same extent as wild-type neutrophils. ${ }^{66}$ On the other hand, changes in the mitochondrial shape from tubular structures to large, unstructured aggregates and Bax relocalization to mitochondria were reported in neutrophils upon TNF- $\alpha$ stimulation. ${ }^{102}$

Strikingly, TNF- $\alpha$ stimulation was shown to induce a rapid rise in the levels of intracellular ROS in neutrophils, which is much higher than upon FAS stimulation but moderate as compared with the rise in ROS levels upon PMA stimulation. ${ }^{66,98,105}$ Generation of ROS is dependent on receptor internalization (unpublished work) and was shown to be mediated by class IA PI3Ks and p38, ${ }^{66,106,107}$ suggesting that TNF- $\alpha$ stimulation in neutrophils results in engagement of intracellular signaling pathways. The generation of ROS has been suggested to be the underlying mechanism for neutrophil survival or death decision upon TNF- $\alpha$ stimulation. ${ }^{97,99}$ In line with these results, we found a clear correlation between death induction upon TNF- $\alpha$ stimulation and the level of ROS generation among different neutrophil donors. ${ }^{66}$ Moreover, neutrophils of CGD patients cannot undergo TNF- $\alpha$-induced cell death ${ }^{66,97}$ indicating a necessity for ROS in TNF- $\alpha$-induced apoptosis.

The interplay between caspase activation and ROS generation upon TNF- $\alpha$ stimulation of neutrophils is controversial. Inhibition of caspases by z-VAD-FMK was shown to reduce extracellular $\mathrm{ROS},{ }^{101}$ suggesting that caspases are upstream of ROS. In contrast, we found that Z-VAD-FMK, at concentrations between 10 and $50 \mu \mathrm{M}$, could not block intracellular ROS; however, inhibition of ROS resulted in reduced caspase activation, ${ }^{66}$ suggesting that $\mathrm{ROS}$ are upstream of caspases.

TNF-related apoptosis-inducing ligand (TRAIL)-induced neutrophil apoptosis. Few reports have investigated 
TRAIL expression and function in neutrophils. Although one study showed expression of all five TRAIL receptors on the neutrophil surface, ${ }^{108}$ a second reported TRAIL-R1, -R2, -R3, -R4 mRNA and TRAIL-R1, -R3, -R4 protein on neutrophil surface. ${ }^{109}$ In contrast, two more recent studies could only detect TRAIL-R2 and -R3 mRNA and protein in neutrophils. ${ }^{75}$ There is also no consistency in the scientific literature about the effect of TRAIL stimulation on neutrophil viability. Although monomeric, that is non-cross-linked, TRAIL does not seem to impact on neutrophil survival, ${ }^{75,109}$ leucine zipper-tagged TRAIL was shown to accelerate apoptosis through TRAIL-R2 in one study, ${ }^{75}$ but did not have a major effect on neutrophil viability in another report. $^{108}$ In contrast, apoptosis was highly increased in neutrophils treated with leucine zipper-tagged TRAIL in combination with chemokine receptor CXCR4 ligation, which was mediated by TRAIL-R1 ligation. ${ }^{108}$ The molecular mechanisms underlying TRAIL-induced neutrophil cell death and the conditions under which it might occur remain to be elucidated.

\section{Endocytosis-Induced Cell Death}

From the sparse information available in the scientific literature, cell death caused by endocytosis, be it bacteriaor virus-induced, seems to share many homologies with apoptosis described following TNF- $\alpha$ stimulation (Figure 2). This may be due to the similarities in molecular mechanisms between endocytosis of pathogens and the endocytosis of activated receptors, such as TNFR. Thus, the death occurring following endocytosis of pathogens carries the signature of apoptosis, yet is accompanied by high ROS generation.

Bacteria-induced apoptosis. In order to fight intruding pathogens, neutrophils phagocytose bacteria, fungi and protozoa, a process that elicits generation of ROS and release of cytotoxic granule components into phagocytic vacuoles. The engulfment of microorganisms by neutrophils was shown to impact on neutrophil viability, be it apoptosis, ${ }^{110,111}$ autophagy ${ }^{112}$ or survival. ${ }^{113}$ For an excellent review on phagocytosis-induced apoptosis and survival, the reader is referred to an article by DeLeo. ${ }^{8}$ In this study, only the main findings over the last few years are summarized.

Phagocytosis of complement (through complement receptor) or IgG (through Fc receptor) opsonised targets trigger rapid neutrophil apoptosis. ${ }^{99,110,114,115}$ Also phagocytosis of microorganisms such as Escherichia coli, Mycobacterium tuberculosis, Streptococcus pyogenes, Burkholderia cepacia, Staphylococcus aureus and Entamoeba histolytica by neutrophils results in apoptosis. In contrast, microbes that survive within neutrophils following phagocytosis, such as Anaplasma phagocyticum, Chlamydia pneumoniae, Neisseria gonorrhoeae inhibit neutrophil apoptosis.

Phagocytosis-induced neutrophil apoptosis is dependent on caspases, as caspase- 8 is processed, caspase- 3 becomes activated ${ }^{111}$ and inhibition of initiator and effector caspases blocks neutrophil apoptosis. ${ }^{111}$ Analogous to TNF- $\alpha$-induced neutrophil apoptosis, ROS generated upon phagocytosis of microorganisms is thought to impact on neutrophil viability, as blocking of ROS generation by inhibition of NADPH oxidase blocks phagocytosis-induced apoptosis. ${ }^{110,111}$ Moreover, neutrophils from CGD patients show reduced apoptosis following phagocytosis as compared with healthy control neutrophils. ${ }^{99}$ It was shown that the bacteria-to-neutrophil ratio dictates in part the level of ROS or caspase activity produced in vitro, which in turn influences cell fate. ${ }^{110}$ In phagocytosis-induced cell death, ROS seems to be upstream of caspases, as ROS inhibition reduced caspase-3 activation. ${ }^{111}$ ROS furthermore trigger the release of cathepsin B from lysosomes which induces cleavage of Bid, results in mitochondrial damage and subsequent caspase activation and apoptosis. ${ }^{40}$

Virus-induced apoptosis. Viral infections of neutrophils can either lead to increased survival or death in neutrophils, depending on the viral strain that targets the neutrophils. One viral strain whose effect on neutrophil viability has been analyzed in more detail is influenza $A$ virus. Influenza $A$ virus enters host cells by clathrin-mediated and non-clathrinmediated endocytosis and escapes from endosomes/ lysosomes by membrane fusion. Incubation of neutrophils with influenza A virus results in increased cell death, ${ }^{114,116}$ which is most pronounced when the cells are co-incubated with influenza A virus and bacteria. ${ }^{114,116}$ Death induced by influenza $A$ virus seems to be apoptosis, as neutrophils showed increased PS exposure without membrane rupture, increased DNA fragmentation and increased caspase-3 activity. ${ }^{116}$ Moreover, apoptosis induced by influenza A virus was blocked by inhibition of NADPH oxidase, suggesting a role for ROS production in this death mechanism. ${ }^{116}$

\section{Other Forms of Neutrophil Death}

Autophagic cell death. Few publications have thus far reported autophagic processes in neutrophils. ${ }^{80,112,117,118}$ It was recently shown that phagocytosis of Escherichia coli or LPS-, zymosan- and IgG-coated beads resulted in LC3 aggregation at neutrophil phagosomes, ${ }^{112,117}$ suggesting a link between phagocytosis of microorganisms and the autophagic machinery. Moreover, stimulation of neutrophils with PMA or Toll-like receptor (TLR) agonists led to vacuole formation, LC3 conversion and LC3 aggregation, thus revealing phagocytosis-independent autophagy in neutrophils. ${ }^{112,117}$ Following either stimulus, the generation of ROS by the neutrophil NADPH oxidase was a prerequisite for these autophagic processes. ${ }^{112,117}$ ROS were also shown to be crucial for Siglec-9- and CD44-induced neutrophil cell death, which was accompanied by vacuolarization of the cytoplasm $^{80,118}$ and thus suggested to be autophagic cell death. ${ }^{119}$ As ROS generation and cell death are closely linked in neutrophils, the autophagic machinery may also be activated as a consequence of elevated ROS levels, in order to decrease cell damage that is caused by the oxidative burst. However, whether autophagy is a death pathway or rescue mechanism in neutrophils remains to be established.

ETosis. Neutrophil extracellular traps (NETs) have recently been added to the arsenal of weapons neutrophils use 
to fight invading pathogens. NET formation occurs after stimulation of neutrophils with PMA, IL-8, LPS, IFN- $\alpha$ or $-\gamma$ plus C5a, GM-CSF plus LPS or C5a, bacteria and fungi. ${ }^{34,120-123}$ NETs have been suggested to consist of nuclear DNA, which is released by dying neutrophils after the rupture of the cell membrane, ${ }^{122}$ a process termed ETosis. ETosis was shown to be distinct from apoptosis or necrosis, ${ }^{121,122}$ yet involves the generation of ROS by the NADPH oxidase. ${ }^{122}$ In keeping with this, neutrophils from CGD patients do not form NETs. ${ }^{122}$ NETs can also be formed by viable neutrophils in a ROS-dependent manner; however, the DNA under these conditions is derived from mitochondria. $^{34}$ Recently, a third type of NET formation was shown to be ROS-independent when neutrophils were stimulated through CXCR2. However, whether this process is dependent on neutrophil death or not was not investigated. ${ }^{124}$

\section{Neutrophil Apoptosis and Pharmacological Intervention}

Therapeutic manipulation of neutrophil viability could be used to control the resolution of inflammation. Due to our knowledge of the molecular mechanisms of apoptosis, several starting-points could be or have been envisaged for targeting neutrophil apoptosis that we would like to briefly discuss in this study (see also Figure 3 ).

Induction of caspase activity. An earlier report has demonstrated that cell-permeable Smac induced caspase-3 activity and neutrophil apoptosis. ${ }^{26}$ Recently, chemical mimetics of Smac have been developed, one of them being BV6. BV6 binds and neutralizes XIAP, therefore increasing effector caspase activity. BV6 was shown to increase cell death of FASL-stimulated hepatocytes. ${ }^{125}$ So far, no reports have shed light on the effect of BV6 on neutrophil viability or on the resolution of inflammation.

Inhibition of Mcl-1. Several inhibitors of Bcl-2 family members have been identified or developed recently, including apogossypol/gossypol, TW-37 and ABT-737. Although gossypol and TW-37 are Bcl-2 inhibitors, ABT737 is an inhibitor of $\mathrm{Bcl}-2, \mathrm{Bcl}-\mathrm{xL}$ and $\mathrm{Bcl}-\mathrm{w}$, but little effect was reported on $\mathrm{Mcl}-1$ or $\mathrm{A} 1$. So far, no selective Mcl-1 inhibitor was reported, and the effect of the Bcl-2 inhibitors on neutrophil viability or inflammation has not been reported.

Increased ROS generation. Although ROS are usually associated with inflammation, increasing evidence suggests that enhanced inflammation occurs in the absence of ROS generated by the NADPH oxidase. For instance, patients with CGD suffer from a variety of inflammatory conditions. ${ }^{126}$ This counter-intuitive finding may be explained by the important role of ROS during neutrophil cell death. To the best of our knowledge, sulfasalazine is the only drug associated with enhanced ROS generation. Sulfasalazine is a sulfonamide that is used primarily in the treatment of inflammatory bowel disease and rheumatoid arthritis. Interestingly, sulfasalazine specifically induces apoptosis in neutrophils, but not in other leukocytes. ${ }^{127}$ By performing inhibitor studies, it was demonstrated that sulfasalazine induces neutrophil apoptosis through activation of tyrosine kinases, PKA and the generation of ROS. ${ }^{127}$

Inhibition of Cdks and PCNA. Recently, it has been shown that neutrophils can be driven to undergo apoptosis by

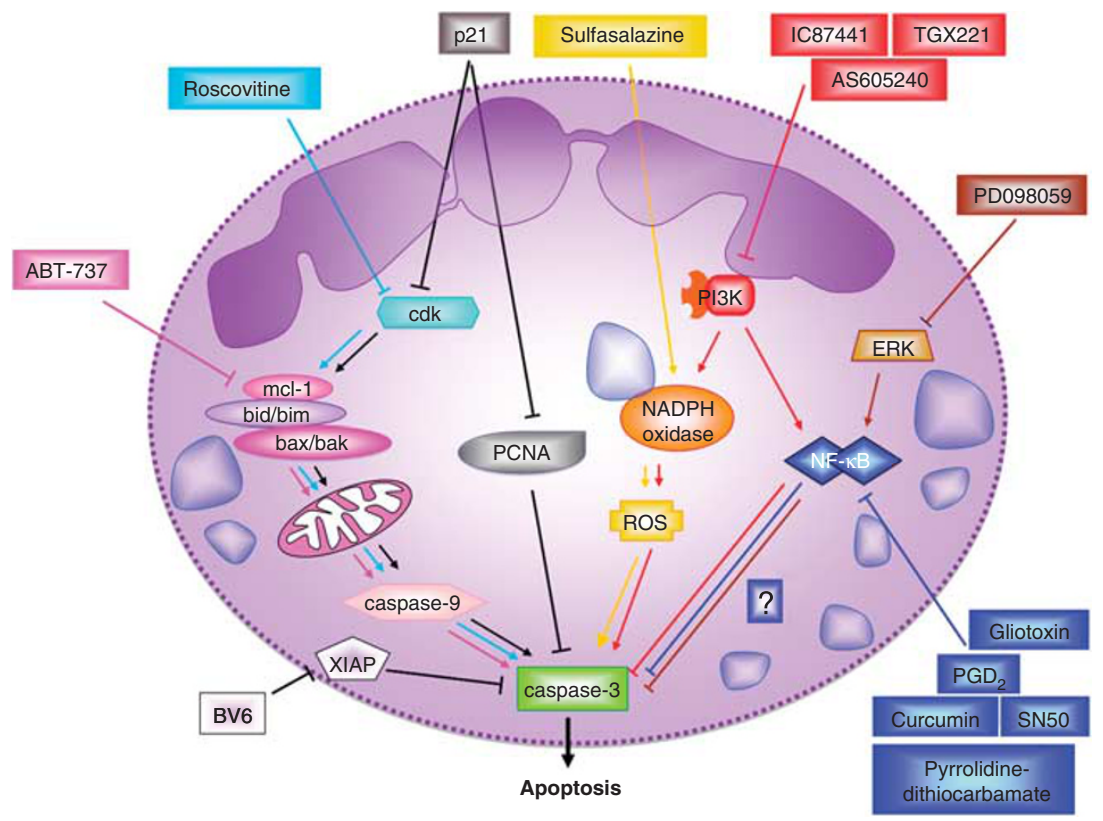

Figure 3 Potential drug strategies to induce neutrophil apoptosis. Various points of attack can be envisioned to pharmacologically induce neutrophil apoptosis. Although some of the strategies would interfere with molecular pathways in many different cell types, others may target specifically neutrophils. It should be noted that under conditions of neutropenia, increased neutrophil survival might be the therapeutic goal (not shown) 
pharmacological inhibition of the Cdks. The Cdk inhibitor R-roscovitine, which accelerates neutrophil apoptosis, promotes the resolution of inflammation in a number of animal models of inflammation. ${ }^{44}$ This finding was surprising, as neutrophils were previously shown to downregulate Cdks during differentiation to mature cells. ${ }^{47} \mathrm{~A}$ peptide of the $\mathrm{Cdk}$ inhibitor p21 was furthermore shown to interfere with binding of PCNA to pro-caspases and to induce neutrophil apoptosis in vitro. ${ }^{46}$ Thus, this $\mathrm{p} 21$ peptide might be a potent inducer of neutrophil apoptosis through interaction with PCNA, but also Cdks.

Inhibition of NF- $\boldsymbol{k}$ B transcription activity. Inhibition of NF$\kappa \mathrm{B}$ can either be achieved by gliotoxin, $\mathrm{SN}-50$, curcumin, pyrrolidin-dithiocarbamate, which inhibit NF- $\kappa \mathrm{B}$ directly, or by $\mathrm{PGD}_{2}$ metabolites, which block the degradation of $\mathrm{I}_{\kappa} \mathrm{B}$. Although gliotoxin and $\mathrm{PGD}_{2}$ were shown to increase neutrophil apoptosis in vitro, ${ }^{71}$ there is in vivo evidence that $\mathrm{PGD}_{2}$ contributes to the resolution of inflammation in a rat model of pleurisy. ${ }^{128}$

MAPK inhibitors. As described above, inhibition of ERK by pharmacological inhibitors prevents GM-CSF-induced neutrophil survival in vitro. ${ }^{58}$ The in vivo efficacy of the MEK/ERK inhibitor PD098059 in the resolution of inflammation was further demonstrated in a rat model of carrageenan-induced pleurisy. ${ }^{129}$ Due to the controversial role of p38 in neutrophil viability, p38 inhibitors such as SB203580 should be used with great care in the treatment of inflammatory conditions.

PI3K inhibitors. Inhibitors against class IB PI3Ks (e.g. AS605240) may be used in inflammatory conditions to dampen recruitment of neutrophils to the site of inflammation. In contrast, the use of class IA PI3K inhibitors should be taken with a pinch of salt due to the important role of class IA PI3Ks in the generation of ROS and their ambiguous involvement in neutrophil cell death.

\section{Conclusions}

Manipulation of neutrophil lifespan by pharmacological substances has been successfully used to control inflammation in animal models. As a variety of neutrophil death mechanisms seem unique to this cell type, future approaches may take advantage of these neutrophil peculiarities. In order to exploit the full potential of regulating neutrophil viability, we need to better understand the molecular mechanisms of life and death decisions in these cells. In particular, efforts should be made to decode the starting point of spontaneous neutrophil apoptosis, to gain insight into the role of ROS in neutrophil death and to investigate in more detail the signaling pathways of apoptosis upon phagocytosis.

\section{Conflict of Interest}

The authors declare no conflict of interest.
Acknowledgements. We apologize to those authors whose work was not cited here due to space limitations. Work in the laboratory of HUS is supported by the Swiss National Science Foundation (Grant No 310030_129640/1). BG is supported by the Roche Research Foundation (Switzerland) and L'Oréal - For Women In Science (Switzerland).

1. Athens JW, Haab OP, Raab SO, Mauer AM, Ashenbrucker H, Cartwright GE et al. Leukokinetic studies. IV. The total blood, circulating and marginal granulocyte pools and the granulocyte turnover rate in normal subjects. J Clin Invest 1961; 40: 989-995.

2. Cartwright GE, Athens JW, Wintrobe MM. The kinetics of granulopoiesis in normal man. Blood 1964; 24: 780-803.

3. Simon HU. Neutrophil apoptosis pathways and their modifications in inflammation. Immunol Rev 2003; 193: 101-110.

4. Pillay J, den Braber I, Vrisekoop N, Kwast LM, de Boer RJ, Borghans JA et al. In vivo labeling with $2 \mathrm{H} 2 \mathrm{O}$ reveals a human neutrophil lifespan of 5.4 days. Blood 2010; 116: 625-627.

5. Furze RC, Rankin SM. The role of the bone marrow in neutrophil clearance under homeostatic conditions in the mouse. Faseb J 2008; 22: 3111-3119.

6. Savill JS, Wyllie AH, Henson JE, Walport MJ, Henson PM, Haslett C. Macrophage phagocytosis of aging neutrophils in inflammation. Programmed cell death in the neutrophil leads to its recognition by macrophages. J Clin Invest 1989; 83: 865-875.

7. Renshaw SA, Timmons SJ, Eaton V, Usher LR, Akil M, Bingle CD et al. Inflammatory neutrophils retain susceptibility to apoptosis mediated via the Fas death receptor. $J$ Leukoc Biol 2000; 67: 662-668.

8. DeLeo FR. Modulation of phagocyte apoptosis by bacterial pathogens. Apoptosis 2004; 9: 399-413.

9. Crawford J, Dale DC, Lyman GH. Chemotherapy-induced neutropenia: risks, consequences, and new directions for its management. Cancer 2004; 100: 228-237.

10. Minchinton RM, Waters AH. Autoimmune thrombocytopenia and neutropenia after bone marrow transplantation. Blood 1985; 66: 752.

11. Bouma G, Ancliff PJ, Thrasher AJ, Burns SO. Recent advances in the understanding of genetic defects of neutrophil number and function. Br J Haematol 2010; 151: 312-326.

12. Aprikyan AA, Liles WC, Park JR, Jonas M, Chi EY, Dale DC. Myelokathexis, a congenital disorder of severe neutropenia characterized by accelerated apoptosis and defective expression of bcl-x in neutrophil precursors. Blood 2000; 95: 320-327.

13. Kroemer G, Galluzzi L, Vandenabeele P, Abrams J, Alnemri ES, Baehrecke EH et al. Classification of cell death: recommendations of the Nomenclature Committee on Cell Death 2009. Cell Death Differ 2009; 16: 3-11.

14. Andina N, Conus S, Schneider EM, Fey MF, Simon HU. Induction of Bim limits cytokinemediated prolonged survival of neutrophils. Cell Death Differ 2009; 16: 1248-1255.

15. Altznauer F, Martinelli S, Yousefi S, Thurig C, Schmid I, Conway EM et al. Inflammationassociated cell cycle-independent block of apoptosis by survivin in terminally differentiated neutrophils. J Exp Med 2004; 199: 1343-1354.

16. Yamashita K, Takahashi A, Kobayashi S, Hirata H, Mesner Jr PW, Kaufmann SH et al. Caspases mediate tumor necrosis factor-alpha-induced neutrophil apoptosis and downregulation of reactive oxygen production. Blood 1999; 93: 674-685.

17. Murphy BM, O'Neill AJ, Adrain C, Watson RW, Martin SJ. The apoptosome pathway to caspase activation in primary human neutrophils exhibits dramatically reduced requirements for cytochrome C. J Exp Med 2003; 197: 625-632.

18. Moulding DA, Akgul C, Derouet M, White MR, Edwards SW. BCL-2 family expression in human neutrophils during delayed and accelerated apoptosis. J Leukoc Biol 2001; 70: 783-792.

19. Maianski NA, Geissler J, Srinivasula SM, Alnemri ES, Roos D, Kuijpers TW. Functional characterization of mitochondria in neutrophils: a role restricted to apoptosis. Cell Death Differ 2004; 11: 143-153.

20. Moulding DA, Quayle JA, Hart CA, Edwards SW. Mcl-1 expression in human neutrophils: regulation by cytokines and correlation with cell survival. Blood 1998; 92: 2495-2502.

21. Epling-Burnette PK, Zhong B, Bai F, Jiang K, Bailey RD, Garcia R et al. Cooperative regulation of $\mathrm{Mcl}-1$ by Janus kinase/stat and phosphatidylinositol 3-kinase contribute to granulocyte-macrophage colony-stimulating factor-delayed apoptosis in human neutrophils. J Immunol 2001; 166: 7486-7495

22. Villunger $A$, Scott $C$, Bouillet $P$, Strasser $A$. Essential role for the $B H 3$-only protein Bim but redundant roles for $\mathrm{Bax}, \mathrm{Bcl}-2$, and $\mathrm{Bcl}-\mathrm{w}$ in the control of granulocyte survival. Blood 2003; 101: 2393-2400.

23. Lindsten T, Ross AJ, King A, Zong WX, Rathmell JC, Shiels HA et al. The combined functions of proapoptotic Bcl-2 family members bak and bax are essential for normal development of multiple tissues. Mol Cell 2000; 6: 1389-1399.

24. Bouillet $P$, Metcalf D, Huang DC, Tarlinton DM, Kay TW, Kontgen F et al. Proapoptotic $\mathrm{Bcl}-2$ relative Bim required for certain apoptotic responses, leukocyte homeostasis, and to preclude autoimmunity. Science 1999; 286: 1735-1738.

25. Kirschnek S, Vier J, Gautam S, Frankenberg T, Rangelova S, Eitz-Ferrer $P$ et al. Molecular analysis of neutrophil spontaneous apoptosis reveals a strong role for the pro-apoptotic BH3-only protein Nova. Cell Death Differ 2011; e-pub ahead of print 10 June 2011; doi:10.1038/cdd 2011.69. 
26. Altznauer F, Conus S, Cavalli A, Folkers G, Simon HU. Calpain-1 regulates Bax and subsequent Smac-dependent caspase-3 activation in neutrophil apoptosis. J Biol Chem 2004; 279: 5947-5957.

27. Kobayashi S, Yamashita K, Takeoka T, Ohtsuki T, Suzuki Y, Takahashi R et al. Calpain-mediated $X$-linked inhibitor of apoptosis degradation in neutrophil apoptosis and its impairment in chronic neutrophilic leukemia. J Biol Chem 2002; 277: 33968-33977.

28. Hamasaki A, Sendo F, Nakayama K, Ishida N, Negishi I, Nakayama K et al. Accelerated neutrophil apoptosis in mice lacking A1-a, a subtype of the bcl-2-related A1 gene. J Exp Med 1998; 188: 1985-1992.

29. Edwards SW, Derouet M, Howse M, Moots RJ. Regulation of neutrophil apoptosis by Mcl-1. Biochem Soc Trans 2004; 32: 489-492.

30. Dzhagalov I, St John A, He YW. The antiapoptotic protein Mcl-1 is essential for the survival of neutrophils but not macrophages. Blood 2007; 109: 1620-1626.

31. Steimer DA, Boyd K, Takeuchi O, Fisher JK, Zambetti GP, Opferman JT. Selective roles for antiapoptotic MCL-1 during granulocyte development and macrophage effector function. Blood 2009; 113: 2805-2815.

32. Borregaard $\mathrm{N}$, Herlin $\mathrm{T}$. Energy metabolism of human neutrophils during phagocytosis. $J$ Clin Invest 1982; 70: 550-557.

33. Fossati G, Moulding DA, Spiller DG, Moots RJ, White MR, Edwards SW. The mitochondrial network of human neutrophils: role in chemotaxis, phagocytosis, respiratory burst activation, and commitment to apoptosis. J Immunol 2003; 170: 1964-1972.

34. Yousefi S, Mihalache C, Kozlowski E, Schmid I, Simon HU. Viable neutrophils release mitochondrial DNA to form neutrophil extracellular traps. Cell Death Differ 2009; 16 1438-1444.

35. Chanock SJ, el Benna J, Smith RM, Babior BM. The respiratory burst oxidase. J Biol Chem 1994; 269: 24519-24522.

36. Sengelov $\mathrm{H}$, Nielsen $\mathrm{MH}$, Borregaard N. Separation of human neutrophil plasma membrane from intracellular vesicles containing alkaline phosphatase and NADPH oxidase activity by free flow electrophoresis. J Biol Chem 1992; 267: 14912-14917.

37. Freitas M, Lima JL, Fernandes E. Optical probes for detection and quantification of neutrophils' oxidative burst. A review. Anal Chim Acta 2009; 649: 8-23.

38. Simon HU, Haj-Yehia A, Levi-Schaffer F. Role of reactive oxygen species (ROS) in apoptosis induction. Apoptosis 2000; 5: 415-418.

39. Conus S, Perozzo R, Reinheckel T, Peters C, Scapozza L, Yousefi S et al. Caspase- 8 is activated by cathepsin $D$ initiating neutrophil apoptosis during the resolution of inflammation. J Exp Med 2008; 205: 685-698.

40. Blomgran R, Zheng $L$, Stendahl O. Cathepsin-cleaved Bid promotes apoptosis in human neutrophils via oxidative stress-induced lysosomal membrane permeabilization. J Leukoc Biol 2007; 81: 1213-1223.

41. Knepper-Nicolai B, Savill J, Brown SB. Constitutive apoptosis in human neutrophils requires synergy between calpains and the proteasome downstream of caspases. $J$ Biol Chem 1998; 273: 30530-30536

42. Squier MK, Sehnert AJ, Sellins KS, Malkinson AM, Takano E, Cohen JJ. Calpain and calpastatin regulate neutrophil apoptosis. J Cell Physiol 1999; 178: 311-319.

43. Yousefi S, Perozzo R, Schmid I, Ziemiecki A, Schaffner T, Scapozza L et al. Calpain-mediated cleavage of Atg5 switches autophagy to apoptosis. Nat Cell Biol 2006; 8: $1124-1132$.

44. Rossi AG, Sawatzky DA, Walker A, Ward C, Sheldrake TA, Riley NA et al. Cyclindependent kinase inhibitors enhance the resolution of inflammation by promoting inflammatory cell apoptosis. Nat Med 2006; 12: 1056-1064.

45. Leitch AE, Riley NA, Sheldrake TA, Festa M, Fox S, Duffin R et al. The cyclin-dependent kinase inhibitor R-roscovitine down-regulates $\mathrm{Mcl}-1$ to override pro-inflammatory signalling and drive neutrophil apoptosis. Eur J Immunol 2010; 40: 1127-1138.

46. Witko-Sarsat V, Mocek J, Bouayad D, Tamassia N, Ribeil JA, Candalh C et al. Proliferating cell nuclear antigen acts as a cytoplasmic platform controlling human neutrophil survival. J Exp Med 2010; 207: 2631-2645.

47. Klausen P, Bjerregaard MD, Borregaard N, Cowland JB. End-stage differentiation of neutrophil granulocytes in vivo is accompanied by up-regulation of p27kip1 and downregulation of CDK2, CDK4, and CDK6. J Leukoc Biol 2004; 75: 569-578.

48. Dibbert B, Weber M, Nikolaizik WH, Vogt P, Schoni MH, Blaser K et al. Cytokine-mediated Bax deficiency and consequent delayed neutrophil apoptosis: a general mechanism to accumulate effector cells in inflammation. Proc Natl Acad Sci USA 1999; 96 13330-13335.

49. Colotta F, Re F, Polentarutti N, Sozzani S, Mantovani A. Modulation of granulocyte survival and programmed cell death by cytokines and bacterial products. Blood 1992; 80: 2012-2020.

50. Brach MA, deVos S, Gruss HJ, Herrmann F. Prolongation of survival of human polymorphonuclear neutrophils by granulocyte-macrophage colony-stimulating factor is caused by inhibition of programmed cell death. Blood 1992; 80: 2920-2924.

51. Lee A, Whyte MK, Haslett C. Inhibition of apoptosis and prolongation of neutrophil functional longevity by inflammatory mediators. J Leukoc Biol 1993; 54: 283-288.

52. Daigle I, Yousefi S, Colonna M, Green DR, Simon HU. Death receptors bind SHP-1 and block cytokine-induced anti-apoptotic signaling in neutrophils. Nat Med 2002; 8: 61-67.

53. Gasmi L, McLennan AG, Edwards SW. The diadenosine polyphosphates Ap3A and Ap4A and adenosine triphosphate interact with granulocyte-macrophage colony-stimulating factor to delay neutrophil apoptosis: implications for neutrophil: platelet interactions during inflammation. Blood 1996; 87: 3442-3449.
54. Lee E, Lindo T, Jackson N, Meng-Choong L, Reynolds P, Hill A et al. Reversal of human neutrophil survival by leukotriene $B(4)$ receptor blockade and 5-lipoxygenase and 5-lipoxygenase activating protein inhibitors. Am J Respir Crit Care Med 1999; 160: 2079-2085.

55. Akgul C, Edwards SW. Regulation of neutrophil apoptosis via death receptors. Cell Mol Life Sci 2003; 60: 2402-2408.

56. Yousefi S, Green DR, Blaser K, Simon HU. Protein-tyrosine phosphorylation regulates apoptosis in human eosinophils and neutrophils. Proc Natl Acad Sci USA 1994; 91: 10868-10872.

57. Wei S, Liu JH, Epling-Burnette PK, Gamero AM, Ussery D, Pearson EW et al. Critical role of Lyn kinase in inhibition of neutrophil apoptosis by granulocyte-macrophage colonystimulating factor. J Immunol 1996; 157: 5155-5162.

58. Klein JB, Rane MJ, Scherzer JA, Coxon PY, Kettritz R, Mathiesen JM et al. Granulocytemacrophage colony-stimulating factor delays neutrophil constitutive apoptosis through phosphoinositide 3-kinase and extracellular signal-regulated kinase pathways. J Immunol 2000; 164: 4286-4291.

59. Cowburn AS, Cadwallader KA, Reed BJ, Farahi N, Chilvers ER. Role of PI3-kinasedependent Bad phosphorylation and altered transcription in cytokine-mediated neutrophil survival. Blood 2002; 100: 2607-2616.

60. Gardai SJ, Hildeman DA, Frankel SK, Whitlock BB, Frasch SC, Borregaard N et al. Phosphorylation of Bax Ser184 by Akt regulates its activity and apoptosis in neutrophils. J Biol Chem 2004; 279: 21085-21095.

61. Martinelli S, Kostylina G, Niggli V, Baumann C, Fey MF, Wendel HG et al. Targeting survivin via PI3K but not $\mathrm{c}$-akt/PKB by anticancer drugs in immature neutrophils. Oncogene 2006; 25: 6915-6923.

62. Derouet M, Thomas L, Cross A, Moots RJ, Edwards SW. Granulocyte macrophage colony-stimulating factor signaling and proteasome inhibition delay neutrophil apoptosis by increasing the stability of Mcl-1. J Biol Chem 2004; 279: 26915-26921.

63. Nijhuis E, Lammers JW, Koenderman L, Coffer PJ. Src kinases regulate PKB activation and modulate cytokine and chemoattractant-controlled neutrophil functioning. $J$ Leukoc Biol 2002; 71: 115-124.

64. Alvarado-Kristensson M, Melander F, Leandersson K, Ronnstrand L, Wernstedt C, Andersson T. p38-MAPK signals survival by phosphorylation of caspase-8 and caspase-3 in human neutrophils. J Exp Med 2004; 199: 449-458.

65. Nahas N, Molski TF, Fernandez GA, Sha'afi RI. Tyrosine phosphorylation and activation of a new mitogen-activated protein (MAP)-kinase cascade in human neutrophils stimulated with various agonists. Biochem J 1996; 318: 247-253.

66. Geering B, Gurzeler U, Federzoni E, Kaufmann T, Simon HU. A novel TNFR1-triggered apoptosis pathway mediated by class IA PI3Ks in neutrophils. Blood 2011; e-pub ahead of print 8 April 2011; doi:10.1182.

67. Frasch SC, Nick JA, Fadok VA, Bratton DL, Worthen GS, Henson PM. p38 mitogenactivated protein kinase-dependent and -independent intracellular signal transduction pathways leading to apoptosis in human neutrophils. J Biol Chem 1998; 273: 8389-8397.

68. El Benna J, Han J, Park JW, Schmid E, Ulevitch RJ, Babior BM. Activation of p38 in stimulated human neutrophils: phosphorylation of the oxidase component p47phox by p38 and ERK but not by JNK. Arch Biochem Biophys 1996; 334: 395-400.

69. Aoshiba K, Yasui S, Hayashi M, Tamaoki J, Nagai A. Role of p38-mitogen-activated protein kinase in spontaneous apoptosis of human neutrophils. J Immunol 1999; 162 : 1692-1700.

70. Rossi AG, Cousin JM, Dransfield I, Lawson MF, Chilvers ER, Haslett C. Agents that elevate cAMP inhibit human neutrophil apoptosis. Biochem Biophys Res Commun 1995 217: 892-899.

71. Ward C, Chilvers ER, Lawson MF, Pryde JG, Fujihara S, Farrow SN et al. NF-kappaB activation is a critical regulator of human granulocyte apoptosis in vitro. J Biol Chem 1999; 274: 4309-4318.

72. Hannah S, Mecklenburgh K, Rahman I, Bellingan GJ, Greening A, Haslett C et al. Hypoxia prolongs neutrophil survival in vitro. FEBS Lett 1995; 372: 233-237.

73. Walmsley SR, Print C, Farahi N, Peyssonnaux C, Johnson RS, Cramer T et al. Hypoxiainduced neutrophil survival is mediated by HIF-1alpha-dependent NF-kappaB activity. J Exp Med 2005; 201: 105-115.

74. Fecho K, Cohen PL. Fas ligand (gld)- and Fas (Ipr)-deficient mice do not show alterations in the extravasation or apoptosis of inflammatory neutrophils. J Leukoc Biol 1998; 64 : 373-383.

75. Renshaw SA, Parmar JS, Singleton V, Rowe SJ, Dockrell DH, Dower SK et al. Acceleration of human neutrophil apoptosis by TRAIL. J Immunol 2003; 170: 1027-1033.

76. Fecho K, Bentley SA, Cohen PL. Mice deficient in fas ligand (gld) or fas (lpr) show few alterations in granulopoiesis. Cell Immunol 1998; 188: 19-32.

77. Kasahara Y, Iwai K, Yachie A, Ohta K, Konno A, Seki H et al. Involvement of reactive oxygen intermediates in spontaneous and CD95 (Fas/APO-1)-mediated apoptosis of neutrophils. Blood 1997; 89: 1748-1753.

78. Scheel-Toellner D, Wang K, Craddock R, Webb PR, McGettrick HM, Assi LK et al. Reactive oxygen species limit neutrophil life span by activating death receptor signaling. Blood 2004; 104: 2557-2564.

79. Fadeel B, Ahlin A, Henter Jl, Orrenius S, Hampton MB. Involvement of caspases in neutrophil apoptosis: regulation by reactive oxygen species. Blood 1998 92: 4808-4818. 
80. von Gunten S, Yousefi S, Seitz M, Jakob SM, Schaffner T, Seger R et al. Siglec- 9 transduces apoptotic and nonapoptotic death signals into neutrophils depending on the proinflammatory cytokine environment. Blood 2005; 106: 1423-1431.

81. Watson RW, O'Neill A, Brannigan AE, Coffey R, Marshall JC, Brady HR et al. Regulation of Fas antibody induced neutrophil apoptosis is both caspase and mitochondrial dependent. FEBS Lett 1999; 453: 67-71.

82. Xu Y, Loison F, Luo HR. Neutrophil spontaneous death is mediated by down-regulation of autocrine signaling through GPCR, PI3Kgamma, ROS, and actin. Proc Natl Acad Sci USA 2010; 107: 2950-2955.

83. Tsuchida $H$, Takeda $Y$, Takei $H$, Shinzawa $H$, Takahashi T, Sendo F. In vivo regulation of rat neutrophil apoptosis occurring spontaneously or induced with TNF-alpha or cycloheximide. J Immunol 1995; 154: 2403-2412.

84. Akgul C, Moulding DA, Edwards SW. Molecular control of neutrophil apoptosis. FEBS Lett 2001; 487: 318-322

85. Maianski NA, Maianski AN, Kuijpers TW, Roos D. Apoptosis of neutrophils. Acta Haematol 2004; 111: 56-66.

86. Daigle I, Simon HU. Critical role for caspases 3 and 8 in neutrophil but not eosinophil apoptosis. Int Arch Allergy Immunol 2001; 126: 147-156.

87. Green DR, Ferguson TA. The role of Fas ligand in immune privilege. Nat Rev Mol Cell Biol 2001; 2: 917-924.

88. Jonsson $\mathrm{H}$, Allen $\mathrm{P}$, Peng SL. Inflammatory arthritis requires Foxo3a to prevent Fas ligand-induced neutrophil apoptosis. Nat Med 2005; 11: 666-671.

89. Watson RW, Rotstein OD, Jimenez M, Parodo J, Marshall JC. Augmented intracellular glutathione inhibits Fas-triggered apoptosis of activated human neutrophils. Blood 1997 89: 4175-4181.

90. Liles WC, Kiener PA, Ledbetter JA, Aruffo A, Klebanoff SJ. Differential expression of Fas (CD95) and Fas ligand on normal human phagocytes: implications for the regulation of apoptosis in neutrophils. J Exp Med 1996; 184: 429-440.

91. Marino MW, Dunn A, Grail D, Inglese M, Noguchi Y, Richards E et al. Characterization of tumor necrosis factor-deficient mice. Proc Natl Acad Sci USA 1997; 94: 8093-8098.

92. Skerrett SJ. Host defenses against respiratory infection. Med Clin North Am 1994; 78 941-966.

93. Iwai K, Miyawaki T, Takizawa T, Konno A, Ohta K, Yachie A et al. Differential expression of bcl-2 and susceptibility to anti-Fas-mediated cell death in peripheral blood lymphocytes, monocytes, and neutrophils. Blood 1994; 84: 1201-1208.

94. Ottonello L, Tortolina G, Amelotti M, Dallegri F. Soluble Fas ligand is chemotactic for human neutrophilic polymorphonuclear leukocytes. J Immunol 1999; 162: 3601-3606.

95. Baumann R, Casaulta C, Simon D, Conus S, Yousefi S, Simon HU. Macrophage migration inhibitory factor delays apoptosis in neutrophils by inhibiting the mitochondriadependent death pathway. Faseb J 2003; 17: 2221-2230.

96. Bruno A, Conus S, Schmid I, Simon HU. Apoptotic pathways are inhibited by leptin receptor activation in neutrophils. J Immunol 2005; 174: 8090-8096.

97. van den Berg JM, Weyer S, Weening JJ, Roos D, Kuijpers TW. Divergent effects of tumo necrosis factor alpha on apoptosis of human neutrophils. J Leukoc Biol 2001; 69: 467-473.

98. Murray J, Barbara JA, Dunkley SA, Lopez AF, Van Ostade $X$, Condliffe AM et al. Regulation of neutrophil apoptosis by tumor necrosis factor-alpha: requirement for TNFR55 and TNFR75 for induction of apoptosis in vitro. Blood 1997: 90: 2772-2783.

99. Coxon A, Rieu P, Barkalow FJ, Askari S, Sharpe AH, von Andrian UH et al. A novel role for the beta 2 integrin $C D 11 b / C D 18$ in neutrophil apoptosis: a homeostatic mechanism in inflammation. Immunity 1996; 5: 653-666.

100. Salamone G, Trevani A, Martinez D, Vermeulen M, Gamberale R, Fernandez-Calotti $P$ et al. Analysis of the mechanisms involved in the stimulation of neutrophil apoptosis by tumour necrosis factor-alpha. Immunology 2004; 113: 355-362.

101. Cowburn AS, White JF, Deighton J, Walmsley SR, Chilvers ER. z-VAD-fmk augmentation of TNF alpha-stimulated neutrophil apoptosis is compound specific and does not involve the generation of reactive oxygen species. Blood 2005; 105: 2970-2972.

102. Maianski NA, Roos D, Kuijpers TW. Tumor necrosis factor alpha induces a caspaseindependent death pathway in human neutrophils. Blood 2003; 101: 1987-1995.

103. Wallach D, Boldin M, Varfolomeev E, Beyaert R, Vandenabeele P, Fiers W. Cell death induction by receptors of the TNF family: towards a molecular understanding. FEBS Lett 1997; 410: 96-106.

104. Cross A, Moots RJ, Edwards SW. The dual effects of TNFalpha on neutrophil apoptosis are mediated via differential effects on expression of Mcl-1 and Bfl-1. Blood 2008; 111 878-884

105. Yuo A, Kitagawa S, Suzuki I, Urabe A, Okabe T, Saito M et al. Tumor necrosis factor as an activator of human granulocytes. Potentiation of the metabolisms triggered by the Ca2+-mobilizing agonists. J Immunol 1989; 142: 1678-1684.

106. Gao XP, Zhu X, Fu J, Liu Q, Frey RS, Malik AB. Blockade of class IA phosphoinositide 3-kinase in neutrophils prevents NADPH oxidase activation- and adhesion-dependen inflammation. J Biol Chem 2007; 282: 6116-6125.
107. Dang PM, Stensballe A, Boussetta T, Raad H, Dewas C, Kroviarski $Y$ et al. A specific p47phox -serine phosphorylated by convergent MAPKs mediates neutrophil NADPH oxidase priming at inflammatory sites. J Clin Invest 2006; 116: 2033-2043.

108. Lum JJ, Bren G, McClure R, Badley AD. Elimination of senescent neutrophils by TNF-related apoptosis-inducing ligand. J Immunol 2005; 175: 1232-1238.

109. Daigle I, Simon HU. Alternative functions for TRAIL receptors in eosinophils and neutrophils. Swiss Med Wkly 2001; 131: 231-237.

110. Watson RW, Redmond HP, Wang JH, Condron C, Bouchier-Hayes D. Neutrophils undergo apoptosis following ingestion of Escherichia coli. J Immunol 1996; 156: 3986-3992.

111. Perskvist N, Long M, Stendahl O, Zheng L. Mycobacterium tuberculosis promotes apoptosis in human neutrophils by activating caspase- 3 and altering expression of Bax/Bcl-xL via an oxygen-dependent pathway. J Immunol 2002; 168: 6358-6365.

112. Mitroulis I, Kourtzelis I, Kambas K, Rafail S, Chrysanthopoulou A, Speletas M et al. Regulation of the autophagic machinery in human neutrophils. Eur J Immunol 2010; 40: 1461-1472.

113. Scaife H, Woldehiwet Z, Hart CA, Edwards SW. Anaplasma phagocytophilum reduces neutrophil apoptosis in vivo. Infect Immun 2003; 71: 1995-2001.

114. Colamussi ML, White MR, Crouch E, Hartshorn KL. Influenza A virus accelerates neutrophil apoptosis and markedly potentiates apoptotic effects of bacteria. Blood 1999; 93: 2395-2403.

115. Gamberale R, Giordano M, Trevani AS, Andonegui G, Geffner JR. Modulation of human neutrophil apoptosis by immune complexes. J Immunol 1998; 161: 3666-3674.

116. Engelich G, White M, Hartshorn KL. Neutrophil survival is markedly reduced by incubation with influenza virus and Streptococcus pneumoniae: role of respiratory burst. J Leukoc Biol 2001; 69: 50-56.

117. Huang J, Canadien V, Lam GY, Steinberg BE, Dinauer MC, Magalhaes MA et al Activation of antibacterial autophagy by NADPH oxidases. Proc Natl Acad Sci USA 2009; 106: 6226-6231.

118. Mihalache CC, Yousefi S, Conus S, Villiger PM, Schneider EM, Simon HU. Inflammationassociated autophagy-related programmed necrotic death of human neutrophils characterized by organelle fusion events. J Immunol 2011; 186: 6532-6542.

119. von Gunten S, Simon HU. Autophagic-like cell death in neutrophils induced by autoantibodies. Autophagy 2007; 3: 67-68.

120. Martinelli S, Urosevic M, Daryadel A, Oberholzer PA, Baumann C, Fey MF et al. Induction of genes mediating interferon-dependent extracellular trap formation during neutrophil differentiation. J Biol Chem 2004; 279: 44123-44132.

121. Brinkmann V, Reichard U, Goosmann C, Fauler B, Uhlemann Y, Weiss DS et al. Neutrophil extracellular traps kill bacteria. Science 2004; 303: 1532-1535.

122. Fuchs TA, Abed U, Goosmann C, Hurwitz R, Schulze I, Wahn V et al. Novel cell death program leads to neutrophil extracellular traps. J Cell Biol 2007; 176: 231-241.

123. Urban CF, Reichard U, Brinkmann V, Zychlinsky A. Neutrophil extracellular traps capture and kill Candida albicans yeast and hyphal forms. Cell Microbiol 2006; 8: 668-676.

124. Marcos V, Zhou Z, Yildirim AO, Bohla A, Hector A, Vitkov L et al. CXCR2 mediates NADPH oxidase-independent neutrophil extracellular trap formation in cystic fibrosis airway inflammation. Nat Med 2010; 16: 1018-1023.

125. Jost PJ, Grabow S, Gray D, McKenzie MD, Nachbur U, Huang DC et al. XIAP discriminates between type I and type II FAS-induced apoptosis. Nature 2009; 460: 1035-1039.

126. Winkelstein JA, Marino MC, Johnston Jr RB, Boyle J, Curnutte J, Gallin Jl et al. Chronic granulomatous disease. Report on a national registry of 368 patients. Medicine (Baltimore) 2000; 79: 155-169.

127. Akahoshi T, Namai R, Sekiyama N, Tanaka S, Hosaka S, Kondo H. Rapid induction of neutrophil apoptosis by sulfasalazine: implications of reactive oxygen species in the apoptotic process. J Leukoc Biol 1997; 62: 817-826.

128. Lawrence T, Willoughby DA, Gilroy DW. Anti-inflammatory lipid mediators and insights into the resolution of inflammation. Nat Rev Immunol 2002; 2: 787-795.

129. Sawatzky DA, Willoughby DA, Colville-Nash PR, Rossi AG. The involvement of the apoptosis-modulating proteins ERK 1/2, Bcl-xL and Bax in the resolution of acute inflammation in vivo. Am J Pathol 2006; 168: 33-41.

130. Hasegawa T, Suzuki K, Sakamoto C, Ohta K, Nishiki S, Hino M et al. Expression of the inhibitor of apoptosis (IAP) family members in human neutrophils: up-regulation of clAP2 by granulocyte colony-stimulating factor and overexpression of clAP2 in chronic neutrophilic leukemia. Blood 2003; 101: 1164-1171.

131. Kostylina G, Simon D, Fey MF, Yousefi S, Simon HU. Neutrophil apoptosis mediated by nicotinic acid receptors (GPR109A). Cell Death Differ 2008; 15: 134-142.

132. Daryadel A, Grifone RF, Simon HU, Yousefi S. Apoptotic neutrophils release macrophage migration inhibitory factor upon stimulation with tumor necrosis factor-alpha. J Biol Chem 2006; 281: 27653-27661. 